\title{
A social marketing approach to improving the nutrition of low-income women and children: an initial focus group study
}

\author{
Sarah E Hampson ${ }^{1,2, *}$, Julia Martin ${ }^{1}$, Jenel Jorgensen ${ }^{1}$ and Mary Barker ${ }^{3}$ \\ 'Oregon Research Institute, 1715 Franklin Boulevard, Eugene, OR 97403, USA: ${ }^{2}$ Department of Psychology, \\ University of Surrey, Guildford, Surrey, GU2 7XH, UK: ${ }^{3}$ Food Choice Group, University of Southampton, \\ Southampton General Hospital, Southampton SO16 6YD, UK
}

Submitted 17 March 2008: Accepted 25 November 2008: First published online 16 February 2009

\begin{abstract}
Objective: To identify approaches for interventions to improve the nutrition of low-income women and children.

Design: Seven focus groups were conducted with low-income women caring for young children in their households. They discussed shopping, eating at home, eating out and healthy eating. The discussions were recorded and subjected to qualitative thematic analysis.

Setting: A semi-rural community in Oregon, USA.

Subjects: There were seventy-four women ( $74 \%$ White), most of whom were 18-29 years old.

Results: Four broad themes were identified, i.e. cost-consciousness, convenience, social influences and health issues.

Conclusions: The target population would benefit from improved understanding of what constitutes a balanced diet, with a greater emphasis on a more central role for fruit and vegetables. To persuade this population to change their eating habits, it will be necessary to convince them that healthful food can be low-cost, convenient and palatable for children. Comparing findings from the present study with a similar one in the UK suggests that the US women faced many of the same barriers to healthy eating but displayed less helplessness.
\end{abstract}

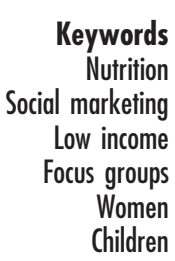

It is increasingly recognized that maternal nutritional status affects the development of the fetus, the newborn's birth weight and the long-term health of the individual ${ }^{(1-3)}$. Improving the nutritional status of women currently of childbearing age, as well as of girls who will become the next generation of mothers, is an essential part of any broad approach to reducing future morbidity and mortality from today's most prevalent chronic conditions. As a first step in the development of intervention strategies to improve the nutritional status of women and girls, a qualitative approach was taken to investigate women's habits of food purchasing and food preparation for their families.

The investigation was guided by a social marketing approach $^{(4)}$. In contrast to 'top down' interventions that originate in health professionals' identification of the problems and solutions ${ }^{(5)}$, this approach begins by studying the audience to which the intervention will be targeted. For example, social marketing has been adopted by the US Centers for Disease Control and Prevention to increase the use of sunscreen, dietary $\mathrm{Ca}$ and vaccinations, as well as to improve self-management of diabetes ${ }^{(6)}$. A number of initiatives to improve nutrition have been based on a social marketing approach ${ }^{(7-9)}$.
The well-established social gradient in health applies to behaviours contributing to morbidity and mortality, including eating habits: those of lower socio-economic status are less likely to follow a healthful diet ${ }^{(10,11)}$ and they are less likely to make food choices in line with dietary guidelines ${ }^{(12)}$. Therefore, the target audience for the present study was identified as low-income women caring for young children. By studying their attitudes, beliefs and behaviours related to food purchasing and preparation, a social marketing intervention to produce behaviour change in this group could be developed from the 'bottom up'.

The study was designed to be broadly comparable to one conducted in Southampton, UK, with one goal being to establish the extent to which disadvantaged women in the USA and the UK face similar challenges to providing healthy diets for themselves and their families ${ }^{(13,14)}$. The aims of the present study were to: (i) discover environmental, social and psychological factors that influence the diets of low-income women; (ii) identify barriers to healthy eating for low-income women; and (iii) generate ideas for ways of overcoming these barriers. The study was conducted in a small town in rural southern Oregon. 


\section{Method}

\section{Participants and recruitment}

Recruitment was primarily through the county Special Supplemental Nutrition Program for Women, Infants, \& Children (WIC), which provides nutrition education and coupons for selected food outlets to low-income mothers. The WIC programme posted sign-up sheets and a poster with a toll-free number and recruited verbally during regularly scheduled nutrition classes. Posters with a tollfree number were also posted at paediatric and medical clinics, low-income service organizations and fitness places, and advertisements were placed on the local Craigslist.org and in the newspaper.

These notices invited women over 18 years of age who were mothers or caring for children under age 13 to call project staff, or to sign up to receive a phone call, if they were interested in attending a meeting to discuss 'grocery shopping, what kids eat, cooking, and other stuff to do with food and families'. Interested women were screened for eligibility by phone (i.e. 18 years or over, meeting the WIC income standard of $185 \%$ of the federal poverty level, mother or caregiver in the household responsible for most household meals, at least one child under 13 years old). Eligible participants were sent a confirmation letter and a copy of the informed consent form. The study received ethical approval from the Human Subjects Committee of the Oregon Research Institute.

\section{Focus group procedures}

The groups were held at a central location during one week in July 2007. Participants began by completing the informed consent form and a demographic information sheet, and they were offered a snack. As an ice breaker, participants were invited to comment on pictures of loaded grocery carts and interiors of refrigerators representing a range of healthy and unhealthy food choices. Thereafter, the two facilitators asked questions and followed up as needed using probes provided in a structured focus group guide. The broad topics were: (i) shopping; (ii) eating at home; (iii) eating out; and (iv) healthy eating. More specific questions included: Where do you shop? What do you like/dislike about these stores? How do you decide what to buy? What do you think about grocery coupons? What do you think about nutrition labels? What do you like/dislike about eating at home? Eating out? When you think of a healthy diet, what comes to mind? What makes it hard for families to eat healthily? What would make it easier to change the way your family eats? The discussions lasted about an hour and a half and were tape-recorded. Participants were compensated \$US 25 for their time plus \$US 10 for child care.

\section{Coding}

A coding scheme was developed in an iterative manner in which the specific themes, ideas and topics relevant to the aims of the study that were identified in one transcript were applied to the next and new codes were added as needed. The coding scheme was 'grounded' in the data in the sense that it emerged from the data rather than from a priori theory ${ }^{(15)}$. A hierarchical approach to grouping these specific codes into broader sub-themes and themes was undertaken jointly by the authors. All transcripts were independently coded by one of the authors. Inter-coder agreements based on two coders' independent coding of two transcripts were $75 \%$ and $73 \%$.

\section{Results}

A total of seventy-four women participated in one of seven focus groups (group size ranged from nine to fourteen participants). The racial/ethnic composition of the sample was 74\% White (non-Hispanic), 12\% Native American, 8\% Hispanic, 4\% Black and 2\% Asian. The majority $(67 \%)$ were young women in the age range of 18-29 years, living with one or more children. Almost all (92\%) had primary responsibility for preparing the household's meals; five women were permitted to participate who reported at the focus group that they did not prepare most of the family meals. Almost all did the food shopping (93\%). The majority (88\%) had completed high school, and $46 \%$ were currently employed. For $82 \%$ of these women, their total family annual income was less than \$US 40000 (see Table 1).

Four broad, interrelated themes were identified that combined many of the narrower themes and sub-themes that cut across the different discussion topics. These were: cost-consciousness, convenience, social influences and health issues (see Table 2).

\section{Cost-consciousness}

These women had limited incomes and, as a result, were highly cost-conscious. Cost was repeatedly mentioned as an important factor in grocery shopping, eating out and eating healthfully.

Cost is a big thing. It would be a lot easier to eat healthier if it was not so expensive.

Trips to the grocery store were timed around pay cheques, and advertised sales often determined where they shopped for groceries and what meat or produce they bought.

When I go shopping I do my meats first because I go for what is cheap and what is going to feed my family and then I get what ever I can get.

They shopped for the best-quality food they could afford, and spoke about their negative experiences with poorquality produce and meat offered at some less expensive supermarkets and discount warehouses. In particular, fresh 
produce was recognized as healthy, but was seen as a poor value if it went bad quickly.

You never know the quality of it. It looks good but then when you get it ... home, the fruits have bruises on them.

Other inexpensive or free sources of food included buying direct from farmers and ranchers, growing your own vegetables, hunting, fishing and gleaning, as well as programmes such as free school lunches. Although

Table 1 Demographic characteristics of the participants: lowincome women $(n 74)$ caring for young children, semi-rural Oregon, USA, July 2007

\begin{tabular}{lr}
\hline Variable & Percentage \\
\hline Age (years) & \\
$18-24$ & 25 \\
$25-29$ & 42 \\
$30-34$ & 12 \\
$35-40$ & 4 \\
$40-44$ & 7 \\
$45-49$ & 3 \\
$\geq 50$ & 7 \\
Educational attainment & \\
Grades 0-8 & 3 \\
Grades 9-11 & 9 \\
High school & 27 \\
Some college & 45 \\
College graduate & 16 \\
Living situation & \\
Partner and child/children & 72 \\
Child/children only & 20 \\
Parent, other relative and child/children & 7 \\
Living alone but carer for child/children in family & 1 \\
Employment & \\
Employed & 46 \\
Homemaker & 38 \\
Unemployed & 8 \\
Student & \\
Retired & 4 \\
Total family annual income (\$US) & 8 \\
<10 000 & \\
$10000-19$ 999 & 3 \\
$20000-29999$ & 7 \\
$30000-39999$ & \\
$40000-49999$ & 20 \\
$50000-59999$ & 27 \\
$\geq 60000$ & 18 \\
\hline
\end{tabular}

some women used coupons from the newspaper to reduce their shopping bills, it was recognized that these promotions were not always good value if they were for more expensive brands or encouraged unnecessary purchases. Eating out was viewed as expensive and a treat.

We eat out about twice a month ... and that is around pay day. And that all depends if we have the extra.

When selecting menu items, portion size and value for money were considerations and many talked about sharing a dish with children to save money. Selecting familiar, liked foods ensured against waste.

\section{Convenience}

Convenient shopping was described as one-stop shopping and not having to drive large distances. However, women were prepared to forego convenience for value by, for example, driving to a particular butcher where they could buy local meat in bulk. Lack of time meant that convenience foods that were simple to prepare were favoured (e.g. frozen burritos).

It's convenient and fast to be unhealthy.

Catering to individual family member's food preferences was an issue. Some accepted the inconvenience of preparing multiple meals in an effort to please their finicky family members, whereas others expected everyone to eat the same meal.

I cook different meals sometimes for the little ones because they don't eat meat a lot.

Trying a new food depended on how convenient it would be to prepare. The level of interest and enthusiasm for cooking varied greatly, but time and energy for cooking were at a premium, particularly for those women who worked outside the home.

I cook on my days off. When I get off work, the last thing I want to do is go in the kitchen and start cooking.

Table 2 Coding scheme: examples of themes and sub-themes organized into the four broad themes

\begin{tabular}{|c|c|c|}
\hline Broad theme & Examples of themes & Examples of sub-themes \\
\hline Cost & $\begin{array}{l}\text { Cost of groceries } \\
\text { Shopping strategy } \\
\text { Cost of eating out } \\
\text { Cost of healthy eating }\end{array}$ & $\begin{array}{l}\text { Value for money } \\
\text { Shop to a list, shop when pay cheque arrives, avoid impulse buying } \\
\text { A treat } \\
\text { Healthy food is more expensive }\end{array}$ \\
\hline Convenience & $\begin{array}{l}\text { Convenient shopping } \\
\text { Convenient foods } \\
\text { Convenient eating out }\end{array}$ & $\begin{array}{l}\text { Kid-friendly, customer service } \\
\text { Healthy foods not convenient } \\
\text { When tired or it is too hot to cook }\end{array}$ \\
\hline Social influences & $\begin{array}{l}\text { On food purchases } \\
\text { On restaurant choices } \\
\text { On food preparation at home }\end{array}$ & $\begin{array}{l}\text { Advertising to kids, kids' and partners' preferences } \\
\text { Family-friendly } \\
\text { Fixing different dishes to accommodate family members' food preferences }\end{array}$ \\
\hline Health issues & $\begin{array}{l}\text { Definition of healthy food } \\
\text { Strategies to increase healthy eating } \\
\text { Advantages }\end{array}$ & $\begin{array}{l}\text { Meat is important, low fat and low sugar } \\
\text { Set a good example, shop without the kids } \\
\text { More energy, avoid obesity }\end{array}$ \\
\hline
\end{tabular}


Eating out provided a convenient solution when they were busy or family members' schedules were complicated. Some women talked about the lack of air conditioning in their homes so, during the hot weather, they avoided having to cook in a hot kitchen by eating out.

\section{Social influences}

Family members, both adults and children, were a strong influence on food purchases and their meal preparation.

I have a hard time getting my kids to eat healthy and please my husband.

There was considerable concern about children being 'picky' eaters and hence not getting enough to eat.

My kid is not a big eater, and picky.

Children tended to eat better if the family, particularly their father, sat down together for a meal.

If my husband and I eat it, my son is more likely to eat it.

Children also influenced shopping by being tempted by attractive food packaging in the store and by wanting to try new items they had seen advertised.

Marketing makes it really hard to eat healthy.

Eating at home provided an opportunity to involve the children in food preparation, which increased the likelihood that they would eat the resulting meal. It also provided valuable family time. Eating out was a treat, but it also had the potential to be stressful if the children misbehaved. Consequently, restaurants that were familyfriendly and drive-throughs were preferred.

I have had to walk out of many restaurants completely mortified.

More generally, family members' likes and dislikes were seen as barriers to trying new foods, particularly more healthful foods. Family members and children's friends were sometimes viewed as negative influences on children's eating habits, with women indicating concern over situations where they lacked control over what their children ate (e.g. school lunches).

\section{Health issues}

The link between good nutrition and health appeared to be clearer for those women who were experiencing health problems in their family, such as diabetes or attention deficit hyperactivity disorder (ADHD).

I have a son who has ADHD and he has other things like that so I have to watch for red dye etc.

Pregnancy was seen as a time to indulge in unhealthy cravings.

With my second daughter, I ate everything and anything. It was a matter of cravings.
Women saw an important connection between eating and health but their understandings of a healthy diet varied considerably. Although some had benefited from nutrition classes provided by WIC, notably absent was knowledge of the current food pyramid, the US government-recommended proportions of different food groups for a healthful diet ${ }^{(16)}$. Instead, these women talked of a balanced meal as comprising equal amounts of meat, vegetables and starch.

I believe you have to have some kind of starch, some kind of vegetable, and some kind of meat. It has got to be balanced.

Some women made use of nutrition labels to identify foods high in contents viewed as unhealthy such as fats and sugars, whereas others found labels difficult to understand. Scepticism over the usefulness of nutritional labels was common.

You try to ... you give up and say 'Oh forget it'.

Eating a more healthful diet was seen as having immediate benefits in the form of more energy for the adults and less hyperactivity for the children. The longterm benefits were avoiding diseases such as diabetes and obesity prevention. Few women expressed concern about their own weight but they did wish to prevent their children from becoming obese adults.

I am trying to shape his idea of nutrition for the future so the things we are teaching him now will carry on through his life.

Eating more healthfully was not an important consideration when eating out. Enjoying a treat, convenience, going to kid-friendly restaurants and concerns over cost were much more significant factors. Participants said they ate healthier meals at home.

When we go out I let the nutrition thing slide. I just want pancakes with whip cream and ice cream ... and I say okay, whatever ... we eat good all the time at home and we have a full course meal. So when we go out to dinner it is like: what do you want?

\section{Group dynamics}

The discussions were lively with a high level of participation. The groups provided women with an opportunity for networking and sharing tips about food shopping and preparation, and some women stayed on to swap phone numbers.

I liked listening to everybody ... and I learned stuff ... it was great.

\section{Discussion}

These low-income women were discerning shoppers, concerned with cost and quality. In this rural location, 
women had additional sources from which to obtain some foods (e.g. local producers, hunting). There was an emphasis on meat as the most important component of the meal, despite it being the most expensive. Levels of enthusiasm, knowledge and interest in cooking were highly variable. When these women went out to eat, it was typically at inexpensive or fast-food restaurants. These women were dealing with a variety of health concerns among their family members that affected their shopping and cooking. Even though participants were recruited primarily through the WIC programme and so were likely to have received some nutrition education, there were numerous understandings of what makes up a healthy diet - none of which was an accurate reflection of the current US government-recommended food pyramid. Nevertheless, these women expressed interest in learning more about healthy eating, and they wanted their children to grow up with good eating habits and to avoid obesity.

\section{Comparison with Southampton, UK}

In a similar focus group study conducted with women of low educational attainment in Southampton, UK, the broad theme that emerged was women's feelings of low control $^{(11,12)}$. Their sense of helplessness was due to cost limiting their food choices, the influence of children and partners, the importance of avoiding food waste (for cost reasons), and their lack of experience with cooking more healthy food. Although the US women in the present study, who were selected on the basis of low income rather than low education, spoke of similar issues (e.g. cost, social influence), the tone was more positive. For example, the US women expressed anger at the poor quality of some of the food offered to them at the less expensive grocery stores and they showed pride in stretching their limited resources. Other differences included more frequent eating out for US families and the belief that meat is the centre of a healthy meal.

\section{Implications for intervention}

A number of themes identified here and in the earlier work in the UK point to intervention approaches that would be applicable in both settings. It will be necessary to demonstrate to low-income women that healthy eating can be achieved without additional cost. However, these women are unlikely to use cheap but healthy foods that take longer to prepare. Given the importance of convenience, they would be more likely to use healthy foods that they perceived as convenience foods (e.g. low-fat macaroni and cheese). Cooking should be simple, such as combining ingredients in a crock pot (slow cooker). Other time- and labour-saving ideas, such as freezing meals for later use, could also be promoted. Healthful foods should be appealing in terms of appearance and taste so that children and other family members will be willing to try them and likely to enjoy them.
There were also intervention implications that may be more specific to the US setting. For example, mothers would welcome new healthful foods that most children would be likely to eat in quantity. Working with children's preferences, not against them, will be a critical element of a successful intervention. Sustaining food that helps children concentrate at school would be desirable. The widespread belief that a balanced meal is one with meat at the centre is a barrier to more healthful and inexpensive eating. Therefore, introducing women to alternative sources of protein that do not involve lengthy or complicated preparation should be an intervention priority, along with education about the amount of protein that is necessary. Promoting healthy food with free samples and/or coupons may encourage women to try new foods. Grocery stores could be a venue to distribute new healthy recipe ideas.

Many women were willing to learn about food and cooking, and enjoyed watching some of the cooking shows on television and reading recipes in magazines and on the Internet. The opportunity for social support created by the focus groups was welcomed, suggesting that an intervention using peer-led support groups would be well-received. Classes are already being provided by the WIC programme, which provides a natural vehicle for further intervention. Incorporating opportunities for children to help should be built into healthful recipes and cooking demonstrations. The present study suggests that television cookery shows with a famous presenter who demonstrates easy and convenient recipes using healthful yet inexpensive ingredients would be well-received. Such shows, along with measures to attract children to these foods (e.g. child-friendly packaging, media campaigns aimed at children) should be a powerful combination.

These focus group discussions revealed that the target population would benefit from a more accurate understanding of good nutrition and what constitutes a balanced diet. However, information alone will not overcome the barriers to healthy eating identified here, which include the perceived cost and inconvenience of more healthful foods, and social influences from family members. Women are highly motivated to do the best for their children, so interventions that appropriately address the issues identified here have the potential to bring about significant changes.

\section{Acknowledgements}

This research was supported by the Barker Foundation. The authors report no conflict of interest. However, the reader should be informed that one of the co-authors, M.B., is the daughter of David Barker. The Barker Foundation funds research on David Barker's theories of fetal programming. M.B. received no financial support in connection with the study reported here. S.E.H. directed all aspects of the research and prepared the first draft of the manuscript. J.M. and J.J. conducted the focus groups, 
coded the transcripts and assisted with manuscript preparation. M.B. collaborated on the design of the study and assisted with manuscript preparation.

\section{References}

1. Barker DJP, Osmond C, Forsén TJ, Kajantie E \& Eriksson JG (2005) Trajectories of growth among children who have coronary events as adults. New Engl J Med 353, 1802-1809.

2. Godfrey KM \& Barker DJP (2000) Fetal nutrition and adult disease. Am J Clin Nutr 71, 5 Suppl., 1344S-1352S.

3. Gluckman PD, Hanson MA, Cooper C \& Thornburg K (2008) Effect of in utero and early-life conditions on adult health and disease. New Engl J Med 359, 61-73.

4. Andreason AR (1995) Marketing Social Change. San Francisco, CA: Jossey-Bass.

5. Young L, Anderson J, Beckstrom L, Bellows L \& Johnson SL (2004) Using social marketing principles to guide the development of a nutrition education initiative for preschool-aged children. J Nutr Educ Behav 36, 250-257.

6. Centers for Disease Control and Prevention (2008) Health Marketing. http://www.cdc.gov/communication/campaigns. htm\#campaigns (accessed January 2009).

7. Lefebvre R \& Flora J (1988) Social marketing and public health intervention. Health Educ Q 15, 299-315.

8. Samuels S (1993) Project LEAN - lessons learned from a national social marketing campaign. Public Health Rep 108, 45-53.
9. Davey Smith G \& Brunner E (1997) Socioeconomic differentials in health: the role of nutrition. Proc Nutr Soc 56, 750-790.

10. Morton J \& Guthrie J (1997) Diet-related knowledge, attitudes, and practices of low-income individuals with children in the household. Family Econ Nutr Rev 10, 2-15.

11. US Department of Agriculture, Food and Consumer Services (1997) Understanding the Food Choices of Lowincome Families: Summary of Findings. Washington, DC: USDA.

12. Turrell G, Hewitt B, Patterson C \& Oldenburg B (2004) A multilevel analysis of socioeconomic (small areas) differences in household food purchasing behavior. J Epidemiol Community Health 58, 208-215.

13. Barker M, Lawrence WT, Skinner TC, Haslam CO, Robinson SM, Inskip HM, Margetts BM, Jackson AA, Barker DJP \& Cooper C; the Food Choice Group, University of Southampton (2008) Constraints on food choices of women with lower educational attainment in the UK. Public Health Nutr 11, 1229-1237.

14. Lawrence W, Skinner TC, Haslam C, Robinson S, Barker DJP, Cooper C, Jackson AA, Barker M \& the Food Choice Group, University of Southampton (2009) Why women of lower educational attainment struggle to make healthier food choices: the importance of psychological and social factors. Psychol Health (In the press).

15. Strauss A \& Corbin J (1998) Basics of Qualitative Research. Grounded Theory Procedures and Techniques, 2nd ed. Newbury Park, CA: Sage.

16. US Department of Agriculture (2008) MyPyramid.gov Steps to a Healthier You. http://www.MyPyramid.gov (accessed January 2009). 